\title{
Social cognition in Williams syndrome: genotype/phenotype insights from partial deletion patients
}

\author{
Annette Karmiloff-Smith ${ }^{1}{ }^{*}$, Hannah Broadbent ${ }^{2}$, Emily K. Farran ${ }^{2}$, Elena Longhi ${ }^{3}$, Dean D'Souza $^{1}$, Kay \\ Metcalfe ${ }^{4}$, May Tassabehji ${ }^{4}$, Rachel Wu ${ }^{1}$, Atsushi Senju ${ }^{1}$, Francesca Happé ${ }^{5}$, Peter Turnpenny ${ }^{6,7}$ and Francis \\ Sansbury ${ }^{6,7}$
}

Birkbeck Centre for Brain and Cognitive Development, University of London, London, UK

2 Institute of Education, University of London, London, UK

${ }^{3}$ Psychology Department, Milan-Bicocca University and Oxford University, Milan, Italy

${ }^{4}$ Genetic Medicine, St. Mary's Hospital, Manchester, UK

${ }^{5}$ Institute of Psychiatry, Kings College London, London, UK

${ }^{6}$ Royal Devon and Exeter Foundation Trust, Exeter, UK

7 Peninsula College of Medicine and Dentistry, Universities of Exeter and Plymouth, Exeter, UK

Edited by:

Daniela Plesa Skwerer, Boston

University, USA

\section{Reviewed by:}

Helen Tager Flusberg, Harvard

University, USA

Chiara Gagliardi, Istituto di Ricovero e

Cura a Carattere Scientifico Eugenio

Medea, Italy

${ }^{*}$ Correspondence:

Annette Karmiloff-Smith, Birkbeck

Centre for Brain and Cognitive

Development, University of London,

32 Torrington Square, London WC1E

7HX, UK.

e-mail: a.karmiloff-smith@bbk.ac.uk
Identifying genotype/phenotype relations in human social cognition has been enhanced by the study of Williams syndrome (WS). Indeed, individuals with WS present with a particularly strong social drive, and researchers have sought to link deleted genes in the WS critical region (WSCR) of chromosome 7q11.23 to this unusual social profile. In this paper, we provide details of two case studies of children with partial genetic deletions in the WSCR: an 11-year-old female with a deletion of 24 of the 28 WS genes, and a 14-year-old male who presents with the opposite profile, i.e., the deletion of only four genes at the telomeric end of the WSCR. We tested these two children on a large battery of standardized and experimental social perception and social cognition tasks - both implicit and explicit - as well as standardized social questionnaires and general psychometric measures. Our findings reveal a partialWS socio-cognitive profile in the female, contrasted with a more autistic-like profile in the male. We discuss the implications of these findings for genotype/phenotype relations, as well as the advantages and limitations of animal models and of case study approaches.

Keywords: social cognition, Williams syndrome, partial deletion patients, genetic disorders, autism spectrum disorders, genotype/phenotype relations

\section{INTRODUCTION}

Williams syndrome (WS) has offered interesting insights into human social cognition in that, despite mild to moderately low IQ, individuals with WS present with an unusually strong social drive (Bellugi et al., 2000; Jones et al., 2000; Plesa Skwerer et al., 2011). A relatively rare neurodevelopmental disorder, WS is caused by haploinsufficiency for certain dosage-sensitive genes among the 28 genes in the WS critical region (WSCR) deleted from one copy of chromosome 7q11.23. WS can now be diagnosed at or shortly after birth, because the genetic basis confirmed by a fluorescence in situ hybridization probe for the missing ELASTIN gene located at the center of the WS deletion - is usually suspected when cardiac problems in the form of supravalvular aortic stenosis and a typical WS facial dysmorphology are noted (Donnai and Karmiloff-Smith, 2000; Hammond et al., 2005). This means that current research not only can target older children and adults, but can also focus on infants and toddlers in the first 2 years of life (e.g., Paterson et al., 1999; Brown et al., 2003; Van Herwegen et al., 2008). This has allowed researchers frequently to note very early signs of the unusual social drive typical of the syndrome, in the form of infants' fascination with, and difficulty disengaging from, human faces.
The delineation of which of the 28 genes contribute to the unusual social phenotype is not straightforward, however, since $98 \%$ of children diagnosed with WS have the full WS deletion. Animal knock-out models have helped narrow the search for candidate genes (e.g., Osborne, 2010, 2012), but all animal models necessarily encounter the limitations that arise when researchers generalize to the neural, cognitive, and behavioral levels in humans. For example, although mouse chromosome $5 \mathrm{G}$ has the same 28 WSCR genes, albeit in reversed order, it cannot be simply assumed that across species the same genes have the same upstream and downstream regulatory pathways nor that they are expressed in homologous brain regions over developmental time. Moreover, single gene knock-outs do not replicate the WS 28 -gene deletion, in that the targeted gene may interact in its expression with other genes in the deleted region. Additionally, it is critical to ensure that the tasks posed to mouse and human have the same cognitivelevel demands, even if behaviorally they seem similar. Nonetheless, mouse models have been helpful in guiding human research in the socio-cognitive domain, although many open questions remain.

Another avenue of promise resides in the study of partial deletion (PD) patients who have smaller numbers of genes deleted in the WSCR, and who differ both from classical WS and from one another in terms of their socio-cognitive phenotypic profiles 
(Frangiskakis et al., 1996; Botta et al., 1999; Tassabehji et al., 1999, 2005; Karmiloff-Smith et al., 2003; Gray et al., 2006; Smith et al., 2009). This paper focuses on two case studies, an 11-year-old female with 24 of the WS genes deleted except for four telomeric genes in the WSCR (up to GTF2IRD1 although this gene is only partially deleted), leaving normal dizygosity of the four remaining telomeric genes, and a 14-year-old male with only those four telomeric genes deleted.

\section{THE PARTIAL DELETION APPROACH}

A number of individuals with PDs in the WSCR have been identified. Some of these patients have just two genes deleted - LIM domain kinase 1 (LIMK1) and ELASTIN (ELN) - while others have three, four, or five deleted (Frangiskakis et al., 1996; Botta et al., 1999; Tassabehji et al., 1999, 2005; Karmiloff-Smith et al., 2003; Gray et al., 2006; Smith et al., 2009; Antonell et al., 2010). These studies have mainly focused on the relationship between ELN and connective tissue defects, between LIMK1 and spatial cognition, and between GTF2IRD1 and craniofacial development in WS. However, with the identification of animal models that have highlighted the role of the Gtf2ird1 gene as a general transcription factor affecting the expression of other genes (Young et al., 2008), PD patients with this gene either deleted or not deleted present interesting comparison cases. The animal model showed that mice with a heterozygous or homozygous disruption of Gtf2irdl exhibit decreased fear and aggression as well as increased social behaviors like excessive grooming of conspecifics, reminiscent of the WS hypersociability and diminished fear of strangers (Young et al., 2008). By contrast, the Gtf2ird1 mice did not present with other core features of WS, such as increased anxiety and problems with spatial learning. The researchers also investigated possible neurochemical bases for the altered social behaviors in the mice and pinpointed increased levels of serotonin metabolites in several brain regions, including the amygdala, frontal cortex, and parietal cortex, which have previously been implicated in fear and aggression. Young et al.'s (2008) results suggest that hemizygosity for GTF2IRD1 in humans may play a role in the complex behavioral phenotype seen in WS, either on its own or in combination with other genes, and that the GTF transcription factors at the telomeric end of the WSCR may have a general influence on social behavior through the alteration of neurochemical pathways.

Deletion of human GTF2I has also been implicated in intellectual difficulties associated with WS (Morris et al., 2003). Morris et al. (2003) assessed five families whose deletions spanned various sections of the WSCR, but with no deletions that included the centromeric FKBP6 or the telomeric GTFI genes. Although all individuals presented with some aspects of the WS profile, none had the fully expressed WS phenotype and none had intellectual difficulties. Given the results of a case study that also found that deletion of FKBP6 did not result in intellectual difficulties (Karmiloff-Smith et al., 2003), the findings of Morris et al. (2003) suggest that GTF2I deletions are the most likely candidates contributing to the intellectual deficits associated with WS (see Antonell et al., 2010 for full review).

Typical and atypical duplications and deletions of the WSCR have also been identified in some individuals presenting with a co-morbid autistic-like phenotype (Berg et al., 2007; Depienne et al., 2007; Malenfant et al., 2011), with GTF2I suggested to be the most likely candidate gene for the expression of autistic-like characteristics in these cases. Thus, although the complete deletion of the WSCR, including the telomeric GTF2I, is likely to result in the classic WS social phenotype, altered expression or duplication of GTF2I at the telomeric end of the WSCR may have disparate effects.

\section{TWO HUMAN CASE STUDIES}

Given the probable importance of the three GTF2 transcription factors for the social phenotype of WS, we focused on two individual case studies, an 11-year-old female (HR in Tassabehji et al., 2005 ) with 24 genes deleted in the WSCR (up to GTF2IRD1) and a 14-year-old male (JB) with only the four telomeric genes deleted. Figure 1 shows the typical WSCR together with the genetic deletions of these two patients (see also Antonell et al., 2010 for other examples of PDs). Psychometric testing and five experimental social perception and social cognition tasks were administered to each participant. In addition, the children's parents were asked to complete seven parent-rated standardized questionnaires, covering a range of social skills from Communication, Social Awareness, Social Cognition, and Daily Living Skills, as well as Anxiety.

\section{MATERIALS AND METHODS PARTICIPANTS}

HR is a female, chronological age at testing: 11 years, 9 months. JB is a male, chronological age at testing: 14 years, 2 months.

\section{MEASURES}

Measures of cognitive functioning included the British Ability Scale-II School Age (BAS-II; Elliot et al., 1996), consisting of a number of tests designed to measure Verbal Ability, Non-Verbal Reasoning Ability, and Spatial Ability. The Raven's Coloured Progressive Matrices (RCPM; Raven et al., 2003) was administered as an additional test of non-verbal ability.

Theory of mind (ToM) and social cognition were assessed experimentally using the Social Attribution Task (Castelli et al., 2002), a measure of an individual's ability to attribute social meaning to animated geometric shapes, and The Strange Stories Task (social and non-social stories; White et al., 2009). We also used two explicit ToM tasks: the Smarties Task and the Where-will-she-look Task (Hogrefe et al., 1986), as well as an implicit ToM task which measures spontaneous anticipatory eye movements rather than




verbal questioning (Senju et al., 2009). The seven standardized questionnaires included the Vineland-II (Sparrow et al., 2005), the Social Responsiveness Scale (SRS; Constantino and Gruber, 2005), the Sociability Questionnaire (Jones et al., 2000), the Children's Communication Checklist-2 (CCC-2; Bishop, 2003), the Children's Behavior Questionnaire (CBQ) - short form (Putman and Rothbart, 2006), the Spence Children's Anxiety Scale (SCAS; Spence, 1998), and the State-Trait Anxiety Inventory for Children (STAIC; Spielberger et al., 1973). Brief descriptions of the experimental tasks and questionnaires are given below.

\section{EXPERIMENTAL TASKS}

\section{Social attribution task}

Participants are shown four short animations which depict two triangles moving about on a computer screen in three different conditions: moving randomly, moving in a goal-directed fashion (chasing, fighting), and moving interactively with implied mental intentions (coaxing, tricking, wanting). In typically developing (TD) controls, the last condition frequently elicits descriptions in terms of mental states that participants attribute to the triangles in an anthropomorphic way. Participants are asked to watch each animation and give a verbal description of what is happening. Analyses are based on the differences between conditions in terms of the mental state descriptors produced.

\section{Strange stories task}

The participant reads (or if there is a reading difficulty, the experimenter reads) a series of short stories, some of which are mental state stories about human interactions/intentions and some physical stories about events. Each story is followed by a critical question (e.g., mental state: "why did he say this?"/"why will he look in the cupboard?"; physical state: "why were all the houses dry?" "why did this happen?") and scored on the basis of mental attributions for social stories and causal inferences for non-social stories. Since the full task is very long, we selected five representative stories of each type of story, i.e., a total of 10 .

\section{Smarties task}

Participants are shown a tube of Smarties (M\&Ms), which the experimenter shakes to indicate that there is something inside. The parent then leaves the room. The child is asked to guess what is inside and always replies "Smarties." The experimenter then opens the tube to reveal its contents: paperclips. The child is then asked: "When your mummy returns, and I show her the closed tube, what will she say is inside?" and to justify their answer. The answer "Smarties" implies that the child understands that the parent's reply depends on what the parent thinks (that she holds a false belief), whereas the answer "paperclips" implies that the child does not have a first order ToM and simply replies on the basis of the state of the real world.

\section{Where-will-she-look task?}

This task is similar to the Smarties Task, but involves a box, a basket and a delicious biscuit. The experimenter puts the biscuit into the basket in front of the parent and child. The parent is then asked to leave the room. The experimenter then moves the biscuit from the basket and puts it into the box. The child is asked where the parent will look for the biscuit when she returns. The answer "in the basket" implies that the child understands that her parent holds a false belief about the biscuit's whereabouts, i.e., that the child has a first order ToM.

\section{Implicit ToM task}

Participants are shown a scenario on a computer screen very similar to the content of the above task, in which a little bear hides an object in one of two containers while a person on the screen is looking on. Then, when the human has her back turned, the bear moves the object into a different container. Eye tracking is used to measure exactly where the participant spontaneously looks in anticipation of which container the experimenter will reach toward as she turns back to retrieve the object.

\section{QUESTIONNAIRES FILLED IN BY THE PARENTS Vineland-II}

The Vineland-II provides a measure of personal and social skills. An Adaptive Behavior Composite (ABC) Score is derived from standard scores in the Communication, Daily Living Skills, and Socialization domains. A separate scaled score for Maladaptive Behavior can also be obtained, which is a composite of Internalizing scores (avoids social interaction, overly anxious, cries/laughs too easily) and Externalizing scores (impulsive, temper tantrums, lies, cheats, steals, says embarrassing things).

\section{Social responsiveness scale}

The SRS is a measure of social reciprocal behavior. It provides a total $T$-score, which is a composite of five sub-scales: Social Awareness (ability to pick up on social cues), Social Cognition (ability to interpret social cues once picked up on), Social Communication (expressive social communicative abilities), Social Motivation (level of motivation to engage in social-interpersonal behaviors), and Autistic Mannerisms [stereotypical behaviors or highly restricted interests characteristic of autism spectrum disorders $(\mathrm{ASD})]$.

\section{Sociability questionnaire}

The Sociability Questionnaire is a 16-item rating scale questionnaire, which includes items relating to social approach behavior and assessment of others' emotional states.

\section{Children's communication checklist-2}

The CCC-2 provides scores for 10 sub-scales as well as a General Communication Composite and Social Interaction Deviance Composite. It is particularly useful for examining language use (pragmatics) rather than language structure.

\section{Children's behavior questionnaire}

The CBQ Short Form is a 94-item assessment of temperament, which provides scores for 15 behavior sub-scales. The behavior scales which are social in nature include: Approach/Positive Anticipation, Anger/Frustration, Falling Reactivity/Soothability, Impulsivity, Inhibitory Control, Sadness, Shyness, Smiling and Laughter. 


\section{Spence children's anxiety scale}

This consists of 38 items yielding a total anxiety score, also broken down into six sub-scores (panic attack and agoraphobia, separation anxiety, physic injury fear, social phobia, obsessive compulsive disorder, and general anxiety/overanxious disorder).

\section{State-trait anxiety inventory for children}

On the basis of 40 items, this provides a general measure of state anxiety and of trait anxiety in school-aged children.

\section{RESULTS}

\section{EXPERIMENTAL TASKS}

\section{Social attribution task}

On this task, HR's storytelling clearly differentiated between happenings suggesting mental states (e.g." "the big triangle wanted to get the little one to stay in his house"/"the little triangle was teasing the other one because she didn't want the big one to kiss her") and those involving physical events ("they're chasing each other"/"I don't know, they just seem to be moving around"). By contrast, JB's descriptions were similar for all types of event, and he failed to use mental state terms to describe any of the triangles' actions.

\section{Social/non-social stories}

On this task, HR's answers again clearly differentiated between events suggesting mental states ("it wasn't true, he didn't really like her hat, but he said that because he didn't want to hurt his aunt" /"he thought the policeman knew he'd stolen stuff from the shop") and the physical stories (e.g., "the little chicks lost their feathers because the big ones attacked them"/ "maybe because the ground was shaking"). Again JB's responses failed to include mental state terms for the social stories nor to differentiate between social and non-social ones, although he was slightly more accurate than HR in inferring why some of the physical states occurred.

\section{Smarties task}

Both HR and JB responded correctly on this task.

\section{Where-will-she-look Task?}

HR clearly distinguished between where her mother thought the biscuit was and where it actually was, laughing as she responded, indicating that she knew her mother had been tricked and would respond incorrectly because of her false belief. By contrast, JB had difficulty with this task, changing his mind about where his father would look. We ran a second version of the task later in the testing session, but JB showed no signs that he understood the mental state implications of the task.

\section{Implicit ToM task}

Both HR's and JB's spontaneous anticipatory eye movements (i.e., first look) suggested that they had some implicit knowledge of the adult's false belief and of where the adult would first reach when she turned back to retrieve the ball.

\section{PSYCHOMETRIC TESTING}

The results of the psychometric testing are summarized in Tables 1 and 2.

\section{British ability scales}

HR's Verbal standard score was 80 (9th percentile). This was calculated from two core scales, Verbal Similarities $(T$-score $=44 ; 27$ th percentile, age equivalent $=10$ years, 3 months) and Word Definitions $(T$-score $=31$; 3 rd percentile, age equivalent $=7$ years, 7 months). In contrast, JB's Verbal standard score was only 59 (0.3 percentile). This was similarly calculated from two core scales, Verbal Similarities ( $T$-score $=28$; 1 st percentile, age equivalent $=8$ years, 3 months $)$ and Word Definitions $(T$-score $=20$; 1 st percentile, age equivalent $=6$ years, 7 months).

On Non-Verbal Reasoning, HR's standard score was 98 (45th percentile). This was calculated from two core scales, on both of which her performance was age-appropriate: Matrices ( $T$ score $=52 ; 58$ th percentile, age equivalent $=12$ years, 9 months) and Qualitative Reasoning ( $T$-score $=46$; 34th percentile, age equivalent $=11$ years, 3 months). In contrast, JB showed impaired performance, with a Non-Verbal Reasoning standard score of only 65 (1st percentile). This was calculated again from two core scales, on both of which his performance was impaired: Matrices $(T$-score $=38 ; 12$ th percentile, age equivalent $=10$ years, 3 months) and Qualitative Reasoning ( $T$-score $=20$; 1 st percentile, age equivalent of 7 years, 1 month). On the Spatial cluster, HR's standard score was 73 (4th percentile), calculated from the core scales Recall of Designs ( $T$-score $=29$; 2 nd percentile; age equivalent $=6$ years, 1 month $)$ and Pattern Construction $(T$-score $=41$; 18 th percentile, age equivalent $=9$ years, 3 months). Of note here, HR's pattern construction $T$-score is below the 20th percentile, and her mean $T$-score of 61, meeting two of the four criteria for the WS cognitive profile (WSCP; Mervis et al., 2000). In contrast, JB's Spatial standard score was 47 ( 0.1 percentile), also calculated from the core scales Recall of Designs ( $T$-score $=20$, 1st percentile; age equivalent $<5$ years) and Pattern Construction $(T$-score $=20$; 1 st percentile, age equivalent $=5$ years, 4 months). His profile did not meet the WSCP.

HR's General Conceptual Ability Score (combination of the three cluster scores) was 80 (9th percentile), with a relative strength in Non-Verbal Reasoning and a significant difference ( 0.05 level) between the Non-Verbal Reasoning cluster scores and the Spatial and Verbal scores. Conversely, JB's GCA score was only 44 (0.1 percentile).

\section{Raven's coloured progressive matrices}

On the RCPM, HR achieved a total score of 32, a chronologically age-appropriate level on this task. In contrast, JB's total score was only 18 , with performance below an age-appropriate level and yielding an estimated mental age of 7 years.

\section{QUESTIONNAIRES}

Comparisons of HR and JB revealed both similarities and differences across different aspects of social ability as evaluated by their parents.

\section{Children's communication checklist-2}

Both children had poor communication results on this test. HR achieved a General Communication Composite (GCC) score of 36 (2nd percentile) and Social Interaction Deviance Composite (SIDC) score of -2 . In combination with a GCC score below 55, 
Table 1 | Psychometric tests.

\begin{tabular}{|c|c|c|c|}
\hline & HR (age $=11.9)$ & $\mathrm{JB}($ age $=14.2)$ & Comments \\
\hline \multicolumn{4}{|l|}{ BAS-II } \\
\hline Verbal & 80 (9th centile) & 59 (0.3 centile) & $\begin{array}{l}\text { HR relative strength in } \\
\text { non-verbal abilities }\end{array}$ \\
\hline Non-verbal & 98 (45th centile) & 65 (1st centile) & \\
\hline Spatial & 73 (4th centile) & 47 ( 0.1 centile) & \\
\hline \multicolumn{4}{|l|}{ RCPM } \\
\hline & $\begin{array}{l}32 \text { (normal range: age } \\
\text { equivalent }=11 \text { years) }\end{array}$ & $\begin{array}{l}18 \text { (below normal range: } \\
\text { age equivalent }=7 \text { years) }\end{array}$ & \\
\hline
\end{tabular}

BAS-II, British Ability Scales-II, standard scores are presented. RCPM, Raven's Coloured Progressive Matrices, raw scores are presented.

Table 2 | Social questionnaires.

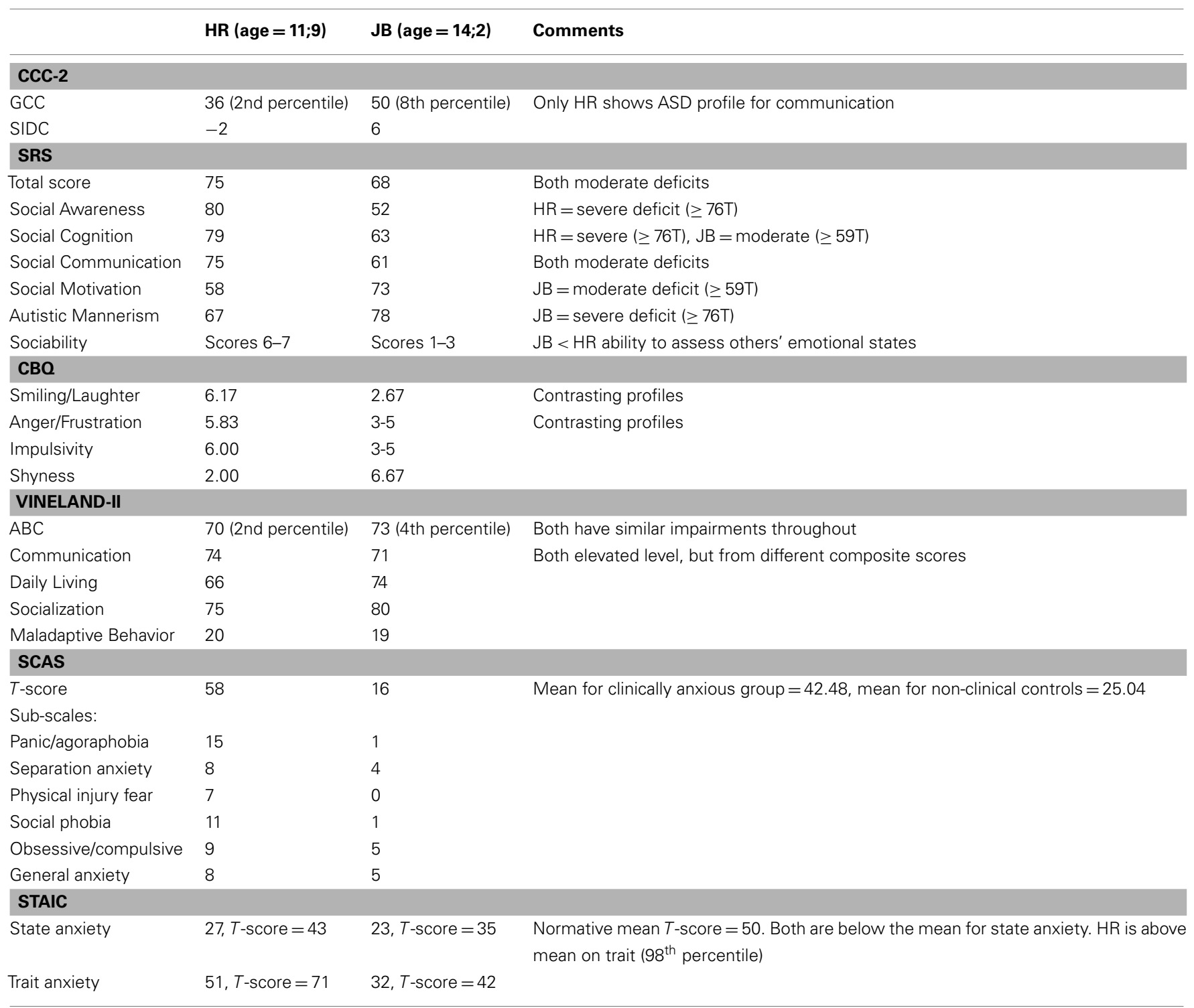

Standard scores are presented for CCC-2, Vineland-II, and STAIC questionnaires, T-scores are presented for SRS and SCAS questionnaires for "Sociability" and "CBO" questionnaires, ranges of raw scores and mean raw scores are presented, respectively. 
a negative SIDC value on the CCC-2 indicates a communicative profile suggestive of an autistic spectrum disorder. However, this was only true of HR, as JB's questionnaire results yielded a GCC score of 50 (8th percentile) and a SIDC score of 6.

\section{Social responsiveness scale}

Composite $T$-scores on the SRS questionnaire painted a somewhat different picture. JB's score was 68, whereas HR achieved a score of 75 (a higher score indicates poorer social responsiveness). Sub-scale $T$-scores over 60 reflect impaired behavior, and both participants' scores fell just short of the severe range. However, it is important to note that these similar composite measures masked different patterns of deficit. For HR, difficulty was apparent for Social Awareness ( $T$-score: 80$)$, Social Cognition ( $T$-score: 79 ), and Social Communication ( $T$-score: 75$)$. The Autistic Mannerisms score ( $T$-score: 67 ) did yield some deficits, but these were relatively less pronounced, whilst Social Motivation ( $T$-score: 58 ) was not impaired in her case. JB presented with the opposite profile, with the most pronounced deficits for Social Motivation ( $T$-score: 73) and Autistic Mannerisms ( $T$-score: 78), borderline impairments for Social Cognition ( $T$-score: 63$)$ and Social Communication ( $T$-score: 61 ). He had no deficit in Social Awareness ( $T$-score: 52 ).

\section{Sociability questionnaire}

Further differences between HR and JB were observed in the ratings given for the Sociability Questionnaire. Ratings ranging from 1 to 7 indicate the likelihood of engaging with others, approaching others, or the probability of commenting on other's emotions. Higher scores indicate higher likelihoods of the behavior occurring, with a score of 4 reflecting typical behavior. HR's questionnaire results yielded mainly $6 \mathrm{~s}$ and $7 \mathrm{~s}$ for both approach behaviors and judgments of emotions, indicative of exaggerated social behaviors seen also in WS. However, HR had scores in the normal range with respect to interactions that involved strangers/unfamiliar adults (approach scores of $4 \mathrm{~s}$ and $5 \mathrm{~s}$ were given). By contrast, JB scored mainly $1 \mathrm{~s}, 2 \mathrm{~s}$, $3 \mathrm{~s}$, which indicates a poor ability to assess another's emotional states and impaired social approach behavior (although scores of 6 were given when approach behavior related to family members).

\section{Vineland questionnaire}

Both HR and JB had low ABC Scores; HR had an ABC Score of 70 (2nd percentile) and JB had an ABC Score of 73 (4th percentile). This questionnaire yielded broadly similar profiles for HR and JB across the three contributing domains. For the Communication domain HR scored 74 (4th percentile), while JB scored 71 (3rd percentile). Scores in the Daily Living Skills and Socialization domains were again similar; Daily Living Skills: HR scored 66 (1st percentile) and JB scored 74 (3rd percentile); Socialization: HR scored 75 (5th percentile) and JB scored 80 (9th percentile). Within the Communication domain, however, HR had a lower age equivalent for Receptive Communication ( 5 years, 6 months) than for Expressive Communication ( 6 years, 6 months) and Written Communication (7 years, 9 months), but for JB Receptive Communication was relatively high ( 9 years, 6 months) compared to Expressive Communication ( 7 years, 6 months) and Written Communication ( 7 years, 9 months).
The Vineland also provides a Maladaptive Behavior score. Both $\mathrm{HR}$ and JB were categorized as having an elevated level of maladaptive behaviors (HR: 20; JB: 19). However, in HR this was driven by her elevated internalizing (score: 19) and externalizing (score: 20) scores, whereas for JB the internalizing score (score: 21) fell in the clinically significant range, but his externalizing score (score: 16) was average.

\section{Children's behavior questionnaire}

Ratings between 1 and 7 are given, with 7 indicating a high level of behavior for that scale. The social scales from this questionnaire revealed relatively high scores for HR for Smiling and Laughter (6.17), Anger/Frustration (5.83), and Impulsivity (6.00), and particularly low scores for Shyness (2.00). By contrast, JB's scores mainly ranged between 3 and 5, with the exception of relatively low scores for Smiling and Laughter (2.67) alongside high Shyness (6.67) scores.

\section{Spence children's anxiety scale}

HR reached a total score of 58, above the normative mean of 42.48 for those considered clinically anxious. Her sub-scores on the scale were: panic and agoraphobia $=15$; separation anxiety $=8$; physical injury fears $=7$; social phobia $=11$; obsessive $/$ compulsive $=9$; and general anxiety/overanxious disorder $=8$. By contrast, JB's total anxiety score was only 16 , which is below the normative mean (25.04) for non-clinical controls. His sub-scores were: panic and agoraphobia $=1$; separation anxiety $=4$; physical injury fears $=0$; social phobia $=1$; obsessive $/$ compulsive $=5$; and general anxiety/overanxious disorder $=5$.

\section{State-trait anxiety inventory for children}

For state anxiety, HR had a raw score of $27(T$-score $=43)$, and JB had a raw score of 23 ( $T$-score $=35)$. These scores are both below the normative mean of 50 for state anxiety. As far as trait anxiety is concerned, HR had a raw score of 51 ( $T$-score $=71)$, which was well above the normative mean (98th percentile), whereas JB had a raw score of $32(T$-score $=42)$.

\section{DISCUSSION}

In summary, at the cognitive level, as measured on the BAS-II, JB presents with more profound impairments than HR, with scores on all his subtests at or below the 1st percentile. The pattern of his subscore tests is unlike that identified as the typical WSCP (Mervis et al., 2000), which at first blush could be expected given the sparing of most of the WS genes. However, other PD patients who do have many WS genes deleted but not the final four to six telomeric genes present with none of the WS phenotype except supravalvular aortic stenosis. Moreover, several groups now believe that the four telomeric genes in the WSCR are those which contribute most significantly to the WSCP. Thus, it could be considered surprising that JB fails to meet the WSCP because he has those four telomeric genes deleted. By contrast, HR's cognitive profile looks more like the WSCP, including a pattern construction score below the 20th percentile and below the mean $T$-score. Non-Verbal Reasoning assessed with the RCPM yields an age-appropriate score for HR, but an estimated mental age of only 7 for JB. From the results of the social questionnaires, both participants have moderate deficits. 
However, on some sub-scales, they present with differing profiles. Of particular note, JB was found to have much more pronounced autistic mannerisms and very reduced social motivation compared to HR. Had the two children been more similar, one might have interpreted these differences in terms of gender. Although the role of gender may be implicated in gene-gene interactions that might account for some of the differences in the two profiles, HR's strong social motivation and JB's severe autistic mannerisms suggest that the dissimilarities between them cannot be due to this factor alone. Indeed, JB's initial diagnosis was ASD but subsequent genetic tests linked him to WS. JB also demonstrated greater impairments in assessing the emotional and mental states of others. On the CBQ, JB had higher levels of shyness, with a lower reported level of smiling/laughter. HR, in contrast, demonstrated high levels of smiling/laughter and low shyness. Nonetheless, it is important to note that the different standardized tasks sometimes varied in their results for the same individual with, for instance, some of HR's some results leaning to autistic-like traits and others to social disinhibition. Similar variations were found in JB's results. Our study therefore highlights the fact that findings from a single standardized task in group studies should be treated with caution, underlining the importance of deriving a general profile from several measures, particularly when using case studies.

The differing patterns were also evident in the results of the experimental ToM and social cognition tasks, with JB revealing considerably more deficits. However, surprisingly, he did succeed on the implicit ToM task, which is the opposite of the pattern typically witnessed in high-functioning individuals with ASD (Senju et al., 2009). It is worth noting that his success on the Smarties Task but failure on the Where-will-she-look Task may be explained by the fact that, although the Smarties Task is supposed to tap ToM attributions, participants can also give the right answer "Smarties" by using long-term semantic knowledge (i.e., Smarties tubes always contain Smarties), if the participant fails to use episodic knowledge of the current social scenario. In other words, although both children passed the Smarties Task, they may have done so by using different cognitive strategies. This, therefore, makes it unsurprising that JB failed on the Where-will-she-look Task, which cannot be solved on the basis of long-term semantic knowledge, but does not explain his success on the implicit ToM task.

One of the advantages (and, of course, limitations) of group studies is that they camouflage individual differences, which are

\section{REFERENCES}

Antonell, A., Del Campo, M., Magano, L. F., Kaufmann, L., de la Iglesia, J. M., Gallastegui, F., Flores, R., Schweigmann, U., Fauth, C., Kotzot, D., and Pérez-Jurado, L. A. (2010). Partial 7q11.23 deletions further implicate GTF2I and GTF2IRD1 as the main genes responsible for the Williams-Beuren syndrome neurocognitive profile. J. Med. Genet. 47, 312-320.

Bellugi, U., Lichtenberger, L., Jones, W., Lai, Z., and St George, M. (2000). The neurocognitive profile of Williams syndrome: a complex

often treated simply as noise. Although case studies allow for a richer database, they obviously suffer from the influence of individual differences in home and school environments, gender and age differences, changing gene expression, and many other individual differences all of which contribute in combined and complex ways to the phenotypic outcome. Nonetheless, we believe that case studies can further our understanding of genotype/phenotype relations as they pertain to social cognition. The important question in the current case study is whether the genetic and sociocognitive similarities and differences between HR and JB help us to hone in on genotype/phenotype relations in the social domain.

Although several animal studies have suggested that when one copy of GTF2IRD1 and GTF2I is deleted, they play a crucial role in social cognition and anxiety in WS, our case study comparisons suggest that they cannot do so alone. HR does not have both these genes fully deleted and yet she presents with many of the characteristics typical of the social phenotype of full-blown WS. Nonetheless, she clearly does not fit the profile in its entirety given her stronger non-verbal compared to linguistic abilities. Moreover, although her parents report that HR talks readily to strangers and is overly friendly, the team of researchers at the lab, who have tested HR repeatedly since she was 28 months of age, have all consistently judged that HR is currently considerably less uninhibited than their other WS participants. By contrast, while JB has these genes deleted, he presents with almost the opposite profile, with numerous autistic-like traits and none of the signs of social disinhibition characteristic of WS. The same holds for social anxiety, with HR scoring very highly and JB completely in the normal range. Hemizygosity for GTF2I has been implicated in elevated levels of sociability typical of WS (Dai et al., 2009). However, the current findings suggest that deletion of the telomeric genes alone, inclusive of GTF2I but without the remaining deleted genes on the entire WSCR, are insufficient to result in this phenotypic outcome.

Moreover, whereas HR has a slight WS facial morphology, JB has none of the facial traits typical of WS. So, although human genetic mapping data have implicated two related genes (GTF2IRD1 and GTF2I) in the cause of some of the key features of WS, including craniofacial dysmorphology, hypersociability, social anxiety, and visuospatial deficits, this case study comparison suggests that, whatever their role, their contribution is likely to be in interaction with other genes proximal of the four telomeric genes in the WS critical region.

Bishop, D. V. M. (2003). The Children's Communication Checklist-2, 2nd Edn. London: The Psychological Corporation.

Botta, A., Novelli, G., Mari, A., Novelli, A., Sabani, M., Korenberg, J., Osborne, L. R., Digilio, M. C., Giannotti, A., and Dallapiccola, B. (1999). Detection of an atypical 7q11.23 deletion in Williams syndrome patients which does not include the STX1A and FZD3 genes. J. Med. Genet. 36, 478-480.

Brown, J. H., Johnson, M. H., Paterson, S. J., Gilmore, R., Longhi, E., and
Karmiloff-Smith, A. (2003). Spatial representation and attention in toddlers with Williams syndrome and Down syndrome. Neuropsychologia 41, 1037-1046.

Castelli, F., Frith, C. D., Happé, F., and Frith, U. (2002). Autism, Asperger syndrome and brain mechanisms for the attribution of mental states to animated shapes. Brain 125, 1839-1849.

Constantino, J. N., and Gruber, C. P. (2005). The Social Responsiveness Scale Manual. Los Angeles, CA: Western Psychological Services. 
Dai, L., Bellugi, U., Chen, X. N., PulstKorenberg, A. M., Järvinen-Pasley, A., Tirosh-Wagner, T., Eis, P. S., Graham, J., Mills, D., Searcy, Y., and Korenberg, J. R. (2009). Is it Williams syndrome? GTF2IRD1 implicated in visual-spatial construction and GTF2I in sociability revealed by high resolution arrays. Am. J. Med. Genet. A 149A, 302-314.

Depienne, C., Heron, D., Betancur, C., Benyahia, B., Trouillard, O., Bouteiller, D., Verloes, A., LeGuern, E., Leboyer, M., and Brice, A. (2007). Autism, language delay and mental retardation in a patient with $7 \mathrm{q} 11$ duplication. J. Med. Genet. 44, 452-458.

Donnai, D., and Karmiloff-Smith, A. (2000). Williams syndrome: from genotype through to the cognitive phenotype. Am. J. Med. Genet. 97, 164-171.

Elliot, C. D., Smith, P., and McCulloch, K. (1996). British Ability Scales II. Windsor: NFER-Nelson.

Frangiskakis, J. M., Ewart, A., Morris, C. A., Mervis, C. B., Bertrand, J., Robinson, B. F., Klein, B. P., Ensing, G., Everett, L. A., Green, E. D., Proschel, C., Gutowski, N. J., Noble, M., Atkinson, D. L., Odelberg, S. J., and Keating, M. T. (1996). LIM-kinasel hemizygosity implicated in impaired visuospatial constructive cognition. Cell 86, 59-69.

Gray, V., Karmiloff-Smith, A., Funnell, E., and Tassabehji, M. (2006). Indepth analysis of spatial cognition in Williams syndrome: a critical assessment of the role of the LIMK1 gene. Neuropsychologia 44, 679-685.

Hammond, P., Hutton, T. J., Allanson, J. E., Buxton, B., Campbell, L. E., Clayton-Smith, J., Donnai, D., Karmiloff-Smith, A., Metcalfe, K., Murphy, K. C., Patton, M., Pober, B., Prescott, K., Scambler, P., Shaw, A., Smith, A. C. M., Stevens, A. F., Temple, I. K., Hennekam, R., and Tassabehji, M. (2005). Discriminating power of localized threedimensional facial morphology. Am. J. Hum. Genet. 77, 999-1010.

Hogrefe, G.-J., Wimmer, H., and Perner, J. (1986). Ignorance versus false belief: a developmental lag in attribution of epistemic states. Child Dev. 57, 567-582.

Jones, W., Bellugi, U., Lai, Z., Chiles, M., Reilly, J., Lincoln, A., and Adolphs, R. (2000). Hypersociability in Williams syndrome. J. Cogn. Neurosci. 12, 30-46.

Karmiloff-Smith, A., Grant, J., Ewing, S., Carette, M. J., Metcalfe, K., Donnai, D., Read, A. P., and Tassabehji, M. (2003). Using case study comparisons to explore genotypephenotype correlations in WilliamsBeuren syndrome. J. Med. Genet. 40, 136-140.

Malenfant, P., Liu, X., Hudson, M. L., Qiao, Y., Hrynchak, M., Riendeau, N., Hildebran, M. J., Cohen, I. L, Chudley, A. E., Forster-Gibson, C., Mickelson, E. C., Rajcan-Separovic, E., Lewis, M. E., and Holden, J. J. (2011). Association of GTF2I in the Williams-Beuren syndrome critical region with autism spectrum disorders. J. Autism Dev. Disord. doi: 10.1007/s10803-011-1389-4. [Epub ahead of print].

Mervis, C. B., Robinson, B. F., Bertrand, J., Morris, C. A., Klein-Tasman, B. P., and Armongstrong, S. C. (2000). The Williams syndrome cognitive profile. Brain Cogn. 44, 604-628.

Morris, C. A, Mervis, C. B., Hobart, H. H., Gregg, R. G., Bertrand, J., Ensing, G. J., Sommer, A., Moore, C. A., Hopkin, R. J., Spallone, P. A., Keating, M. T., Osborne, L., Kimberley, K. W., and Stock, A. D. (2003). GTF2I hemizygosity implicated in mental retardation in Williams syndrome: genotype-phenotype analysis of five families with deletions in the Williams syndrome region. Am. J. Med. Genet. A 123A, 45-59.

Osborne, L. R. (2010). Animal models of Williams syndrome. Am. J. Med. Genet. C Semin. Med. Genet. 154C, 209-219.

Osborne, L. R. (2012). "Genes: the gene expression approach," in $\mathrm{Neu}$ rodevelopmental Disorders Across the Lifespan: A Neuroconstructivist Approach, eds E. K. Farran and A. Karmiloff-Smith (Oxford: Oxford University Press), 59-81.

Paterson, S. J., Brown, J. H., Gsödl, M. K., Johnson, M. H., and KarmiloffSmith, A. (1999). Cognitive modularity and genetic disorders. Science 286, 2355-2358.

Plesa Skwerer, D., Ammerman, E. André, M. C., Ciciolla, L., Fine, A. B., and Tager-Flusberg, H. (2011). A multimeasure approach to investigating affective appraisal of social information in Williams syndrome. J. Neurodev. Disord. 3, 325-334.

Putman, S. P., and Rothbart, M. K. (2006). Development of short and very short forms of the Children's Behaviour Questionnaire. J. Pers. Assess. 87, 103-113.

Raven, J., Raven, J. C., and Court, J. H. (2003). Manual for Raven's Progressive Matrices and Vocabulary Scales. San Antonio, TX: Harcourt Assessment.

Senju, A., Southgate, V., White, S., and Frith, U. (2009). Mindblind eyes: an absence of spontaneous theory of mind in Asperger syndrome. Science 325, 883-885.

Smith, A. D., Gilchrist, I. D., Hood, B., Tassabehji, M., and KarmiloffSmith, A. (2009). Inefficient search of large-scale space in Williams Syndrome: further insights on the role of LIMK1 deletion in deficits of spatial cognition. Perception 38, 694-701.

Sparrow, S. S., Cicchetti, D. V., and Balla, D. A. (2005). Vineland-II Adaptive Behaviour Scales, 2nd Edn. Minneapolis, MN: Pearson Assessment.

Spence, S. H. (1998). A measure of anxiety symptoms among children. Behav. Res. Ther. 36, 545-566.

Spielberger, C. D., Edwards, C. D. Lushene, R. E., Montuori, J., and Platzek, D. (1973). Preliminary Manual for the State-Trait Anxiety Inventory for Children. Palo Alto, CA: Consulting Psychologists Press.

Tassabehji, M., Hammond, P., Karmiloff-Smith, A., Metcalfe, K., Thompson, P., Durkin, M., Thorgeisson, S., Rucka, A., Hutton, T., Hogan, A., Stewart, H., Read, A. P., Maconochie, M., and Donnai, D. (2005). GTF2IRD1 in craniofacial development of humans and mice. Science 310, 1184-1187.

Tassabehji, M., Metcalfe, K., KarmiloffSmith, A., Carette, M. J., Grant, J., Dennis, N., Reardon, W., Splitt, M., Read, A. P., and Donnai D. (1999). Williams syndrome: use of chromosomal microdeletions as a tool to dissect cognitive and physical phenotypes. Am. J. Hum. Genet. 64, 118-125.

Van Herwegen, J., Ansari, D., Xu, F., and Karmiloff-Smith, A. (2008). Small and large number processing in infants and toddlers with Williams syndrome. Dev. Sci. 11, 637-643.

White, S., Hill, E., Happe, F., and Frith, U. (2009). Revisiting the strange stories: revealing mentalizing impairments in autism. Child Dev. 80, 1097-1117.

Young, E. J., Lipina, T., Tam, E., Mandel, A., Clapcote, S. J., Bechard, A. R., Chambers, J., Mount, H. T. J., Fletcher, P. J., Roder, J. C., and Osborne, L. R. (2008). Reduced fear and aggression and altered serotonin metabolism in Gtf2ird1targeted mice. Genes Brain Behav. 7, 224-234.

Conflict of Interest Statement: The authors declare that the research was conducted in the absence of any commercial or financial relationships that could be construed as a potential conflict of interest.

Received: 30 January 2012; paper pending published: 05 April 2012; accepted: 10 May 2012; published online: 30 May 2012.

Citation: Karmiloff-Smith A, Broadbent $H$, Farran EK, Longhi E, D'Souza D, Metcalfe K, Tassabehji M, Wu R, Senju A, Happé F, Turnpenny $P$ and Sansbury $F$ (2012) Social cognition in Williams syndrome: genotype/phenotype insights from partial deletion patients. Front. Psychology 3:168. doi: 10.3389/fpsyg.2012.00168 This article was submitted to Frontiers in Developmental Psychology, a specialty of Frontiers in Psychology.

Copyright (C) 2012 Karmiloff-Smith, Broadbent, Farran, Longhi, D'Souza, Metcalfe, Tassabehji, Wu, Senju, Happé, Turnpenny and Sansbury. This is an open-access article distributed under the terms of the Creative Commons Attribution Non Commercial License, which permits non-commercial use, distribution, and reproduction in other forums, provided the original authors and source are credited. 